\title{
DESENVOLVIMENTO DO PROCESSO DE LAMINAÇÃO DO AÇO PARA A PRODUÇÃO DO VERGALHÃO CA50 $32 \mathrm{~mm} *$
}

Márcio de Fátima Rosa ${ }^{1}$ Ademir de Oliveira Junior ${ }^{2}$ Aline da Costa Miranda Lima ${ }^{3}$

Resumo

Os vergalhões CA50 32mm em barras produzidos via Leito de Resfriamento na CSN Aços Longos iniciaram sua produção em 2015 e para a produção em escala industrial necessitou-se elaborar um experimento para a definição do aço a ser empregado e os parâmetros de processo para atingimento das propriedades mecânicas para atendimento a NBR 7480 . Estes produtos sofrem tratamento térmico de resfriamento a água ou não em função da composição química do aço. Através da realização de testes de laminação de 4 tipos de aço tornou-se possível reduzir a heterogeneidade das propriedades mecânicas e definir os parâmetros de processo.

Palavras-chave: Thermex; Vergalhão em barra.

\section{STEEL ROLLING PROCESS DEVELOPMENT FOR PRODUCTION CA50 REBAR 32mm}

\begin{abstract}
CA50 32mm rebars bars via Cooling Bed CSN Long Steel began production in 2015 and for the production on an industrial scale needed to prepare an experiment for the steel definition to be used and the process parameters for achieving the properties mechanics to reach the NBR 7480 . These products undergo heat treatment cooling water or not depending on the chemical composition of the steel. By performing the 4 kinds of steel lamination tests it became possible to reduce the heterogeneity of mechanical properties and set the process parameters.
\end{abstract}

Keywords: Thermex; Rebar.

1 Técnico de Garantia da Qualidade, Gerência Técnica, CSN Aços Longos, Volta Redonda, Brasil.

2 Técnico de Desenvolvimento Especialista, Gerência Técnica, CSN Aços Longos, Volta Redonda, Brasil.

3 M.Sc. em Engenharia Metalúrgica, Especialista, Gerência de Laminação, CSN Aços Longos, Volta Redonda, Brasil. 


\section{INTRODUÇÃO}

Deformação a quente é aquela realizada a temperaturas absolutas maiores que $60 \%$ da temperatura absoluta de fusão do material. A deformação aplicada a temperaturas tão elevadas leva a mudança de forma desejada e induz alterações metalúrgicas estruturais e subestruturais ativadas termicamente. [1]

A laminação é um dos principais processos industriais de conformação a quente sendo a mesma subdividida em dois grupos de acordo com o seu produto final: planos ou não planos. Estes últimos são também conhecidos como produtos longos. [1] Sendo assim, na Laminação a Quente de Longos, os tarugos são reaquecidos até temperaturas elevadas, para sua austenitização, em seguida submetidos a sequências de deformações, que envolvem as etapas de desbaste, intermediário e acabamento. A barra continuando o processo, após o acabador, passa pelo sistema de resfriamento forçado, cuja finalidade é aumentar a resistência e formar propriedade mecânicas de soldabilidade, essencial para a construção civil.

No presente trabalho são apresentadas o processo de comissionamento do produto CA50 32mm foi realizado teste em 4 tipos de aços, sendo dois tipos de aço microligado e dois ao carbono. O desenvolvimento do processo com 0 objetivo de atender as propriedades mecânicas conforme NBR7480 para a correta parametrização do processo e comercialização do produto.

\section{MATERIAIS E MÉTODOS}

Para analisar o impacto da pressão da água no sistema de tratamento térmico thermex sobre as propriedades mecânicas das barras retas nervuradas produzidas com bitola $32 \mathrm{~mm}$ e analisar as propriedades de aço microligado sem 0 tratamento thermex, via leito de resfriamento. $E$ paralelamente analisar 0 comportamento mecânico dos equipamentos durante a produção do CA50 $32 \mathrm{~mm}$.

Definir e aplicar diferentes pressões de água nos 3 trechos do sistema thermex para os aços 1024 e 1030, posteriormente recolher amostras no Leito de Resfriamento e elaborar ensaio mecânico e análise micrográfica. Para os aços microligados não haverá tratamento térmico com água, seguindo direto para o leito de resfriamento.

Para o teste serão enfornados 4 tarugos de cada grau (1030, 1630, 1635 e 1024). Utilizar 5 barras de sacrifício para acerto de bitola. Após o resfriamento das barras nervuradas será retirada as amostras para ensaios mecânicos (tração e dobramento), além de análises micrográficas.

\section{RESULTADOS E DISCUSSÃO}

Dos resultados obtidos notou-se uma heterogeneidade de resultados entre os aços ao carbono e aços ligados. Assim como os resultados dos ensaios obtidos anteriormente, realizados pelos técnicos do laboratório de ensaios mecânicos durante a produção do vergalhão, apresentou-se variações nos limites de escoamento, limite de resistência e alongamento dentro de uma mesma espira. 


\subsection{Resultados Aço 1630D}

\begin{tabular}{|c|c|c|c|c|c|c|c|c|}
\hline $\begin{array}{l}\text { Corrida - } \\
\text { Grau do } \\
\text { aço }\end{array}$ & Peça & $\begin{array}{c}\text { Após } \\
\text { lam.intermediário } \\
\text { (Bar) }\end{array}$ & $\begin{array}{l}\text { Trecho } 1 \\
\text { (Bar) }\end{array}$ & $\begin{array}{c}\text { Trecho } 2 \\
\text { (Bar) }\end{array}$ & & $\begin{array}{l}\text { Trecho } 3 \\
\text { (Bar) }\end{array}$ & \multicolumn{2}{|c|}{$\begin{array}{c}\text { Temperatura na } \\
\text { entrada do leito }\left({ }^{\circ} \mathrm{C}\right)\end{array}$} \\
\hline \multirow{10}{*}{$\begin{array}{l}\text { A00431 } \\
1630 \mathrm{D}\end{array}$} & 01 & \multirow[t]{4}{*}{0,4} & \multirow[t]{4}{*}{ Sem água } & \multirow[t]{4}{*}{ Sem água } & & \multirow[t]{4}{*}{ Sem água } & & - \\
\hline & 02 & & & & & & & - \\
\hline & 03 & & & & & & & - \\
\hline & 04 & & & & & & & - \\
\hline & \multicolumn{8}{|c|}{ Pressões e Temperaturas } \\
\hline & Peça & LE $\left(\mathbf{k g f} / \mathrm{mm}^{2}\right)$ & $\operatorname{LR}\left(\mathbf{k g f} / \mathrm{mm}^{2}\right)$ & LR/LE & $\mathrm{Al}(\%)$ & $\begin{array}{r}\text { Massa } \\
(\mathrm{kg} / \mathrm{r}\end{array}$ & $\begin{array}{l}\text { near } \\
\text { l) }\end{array}$ & Dobramento \\
\hline & 01 & 45,1 & 63,8 & 1,414 & - & 5,0 & & Ok \\
\hline & 02 & - & - & - & - & - & & - \\
\hline & 03 & 47,9 & 68,0 & 1,420 & - & 6,1 & & Ok \\
\hline & 04 & - & - & - & - & - & & - \\
\hline
\end{tabular}

Figura 1. Parâmetros de processo e resultados obtidos na laminação do aço 1630.

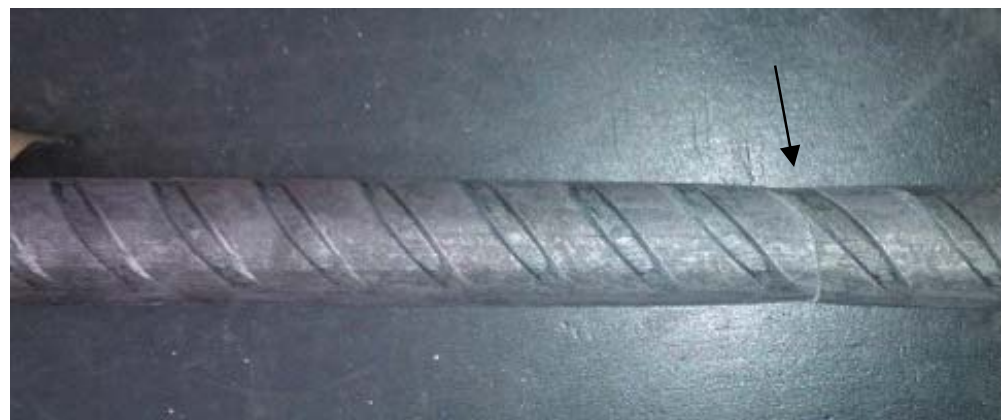

Figura 2. Peça 01 aço 1630D, sem frisos laterais, mostrando a estricção do material.

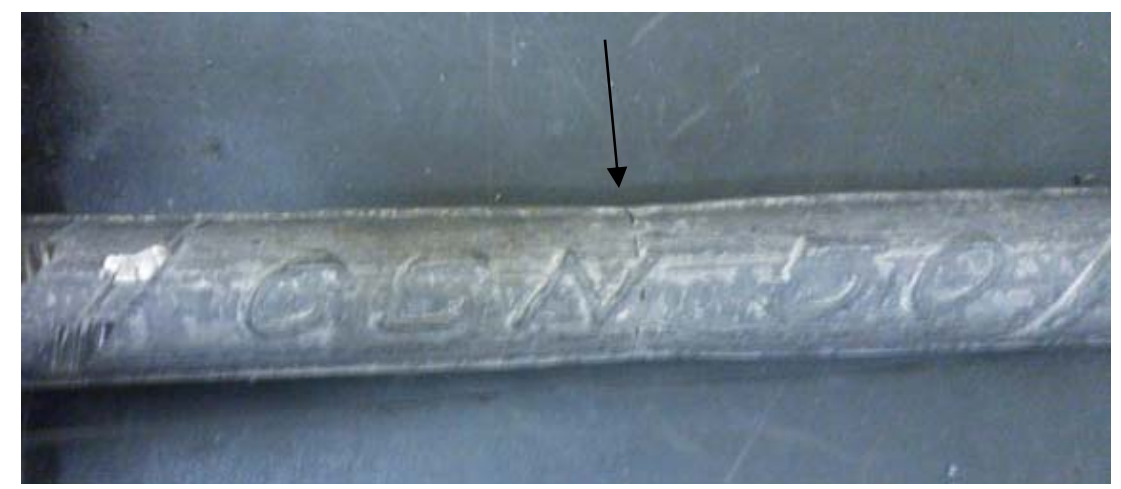

Figura 3. Peça 03 aço 1630D, com frisos, mostrando a estricção do material. 


\subsection{Resultados Aço 1635D}

\begin{tabular}{|c|c|c|c|c|c|c|c|c|}
\hline $\begin{array}{l}\text { Corrida - } \\
\text { Grau do } \\
\text { aço }\end{array}$ & $\begin{array}{c}\mathrm{Peç} \\
\mathrm{a}\end{array}$ & $\begin{array}{c}\text { Após } \\
\text { lam.intermediário } \\
\text { (Bar) }\end{array}$ & $\begin{array}{l}\text { Trecho } 1 \\
\text { (Bar) }\end{array}$ & $\begin{array}{l}\text { Trechc } \\
\text { (Bar }\end{array}$ & & $\begin{array}{l}\text { Trecho } 3 \\
\text { (Bar) }\end{array}$ & $\begin{array}{l}\text { Tel } \\
\text { en }\end{array}$ & $\begin{array}{l}\text { peratura na } \\
\text { ada do leito } \\
\left({ }^{\circ} \mathrm{C}\right)\end{array}$ \\
\hline \multirow{10}{*}{$\begin{array}{c}\text { A00395 } \\
1635 D\end{array}$} & 01 & \multirow[t]{4}{*}{0,4} & \multirow[t]{4}{*}{ Sem água } & \multirow{4}{*}{\multicolumn{2}{|c|}{ Sem água }} & \multirow[t]{4}{*}{ Sem água } & & - \\
\hline & 02 & & & & & & & - \\
\hline & 03 & & & & & & & - \\
\hline & 04 & & & & & & & 980 \\
\hline & \multicolumn{8}{|c|}{ Pressões e Temperaturas } \\
\hline & $\begin{array}{c}\text { Peç } \\
a\end{array}$ & LE (kgf/mm²) & $\mathrm{LR}^{*}\left(\mathrm{kgf} / \mathrm{mm}^{2}\right)$ & LR/LE & $\mathrm{Al}(\%)$ & \multicolumn{2}{|c|}{$\begin{array}{l}\text { Massa linear } \\
(\mathrm{kg} / \mathrm{m})\end{array}$} & $\begin{array}{c}\text { Dobramen } \\
\text { to }\end{array}$ \\
\hline & 01 & 52,7 & 72,0 & 1,366 & - & \multicolumn{2}{|c|}{6,37} & Ok \\
\hline & 02 & - & - & - & - & \multicolumn{2}{|c|}{-} & - \\
\hline & 03 & - & - & - & - & \multicolumn{2}{|c|}{-} & - \\
\hline & 04 & 54,9 & 71,1 & 1,295 & - & \multicolumn{2}{|c|}{6,29} & Ok \\
\hline
\end{tabular}

Figura 4. Parâmetros de processo e resultados obtidos na laminação do aço 1635.

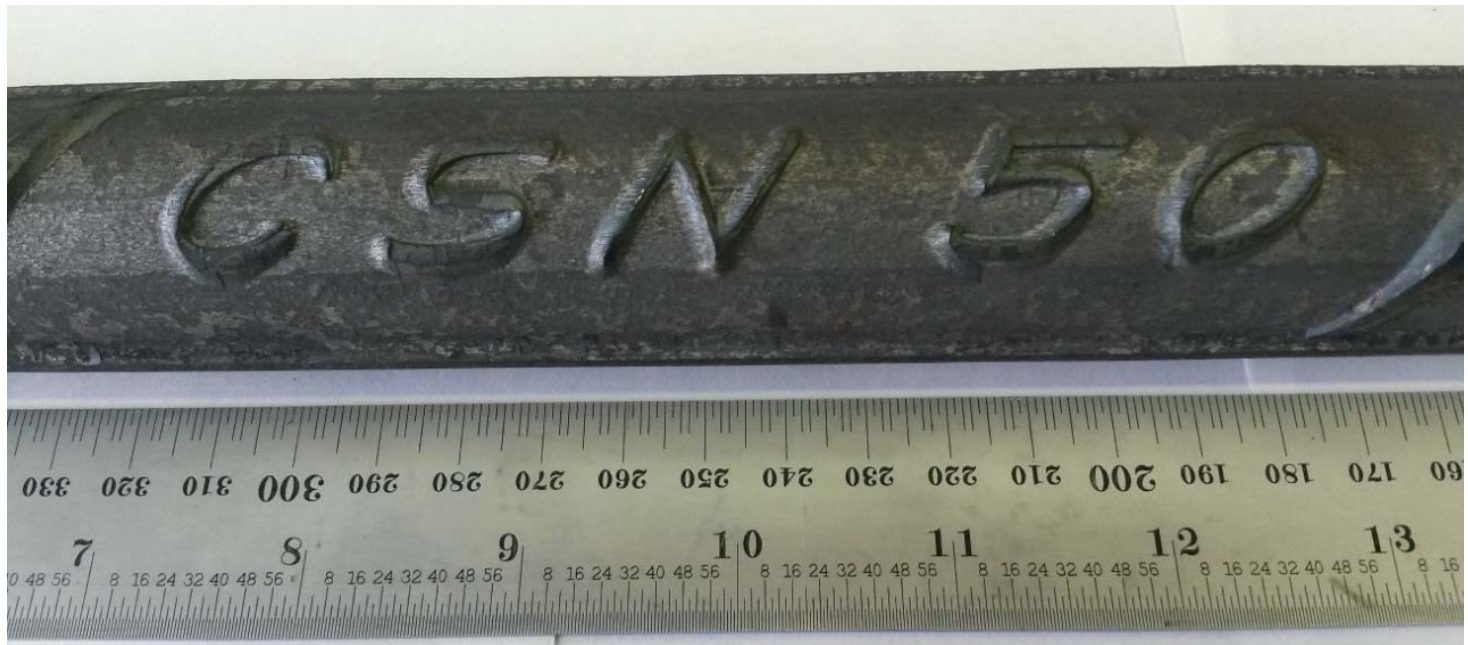

Figura 5. Amostra do aço 1635D - detalhe da logomarca CSN 50.

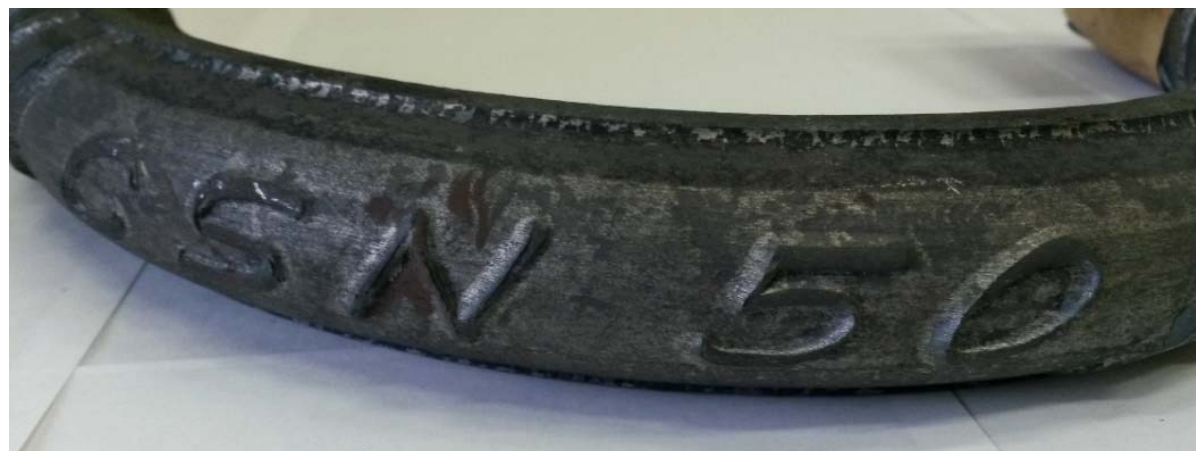

Figura 6. Aspecto da região da logomarca após o ensaio de dobramento do aço 1635D. 


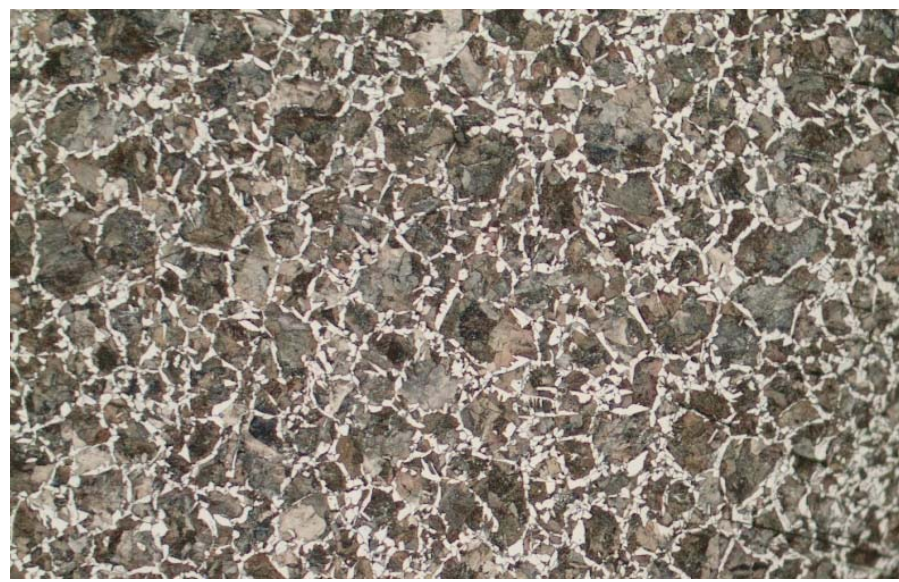

Figura 7. Metalografia do aço na borda 1635D - 100x.

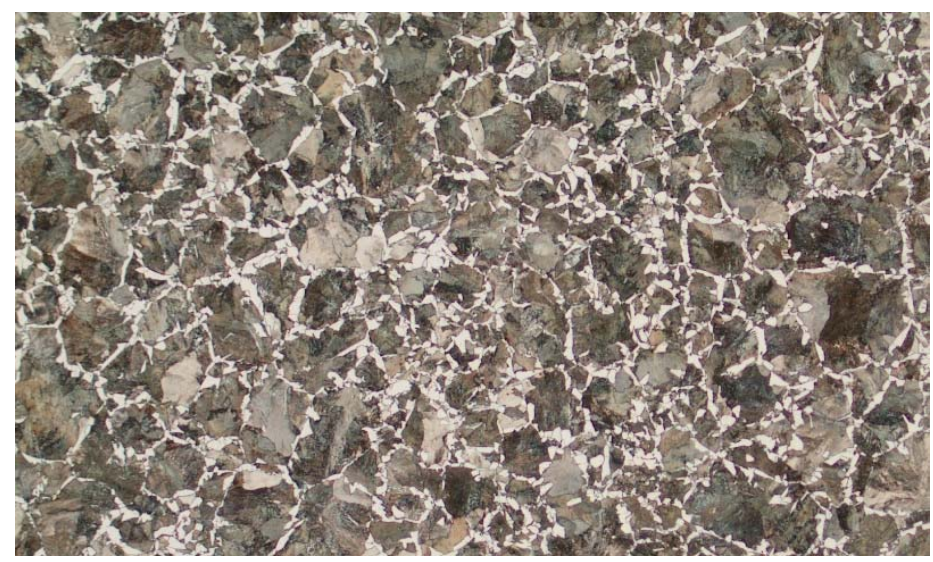

Figura 8. Metalografia do aço no centro 1635D - 100x.

\subsection{RESULTADOS AÇO 1030D}

\begin{tabular}{|c|c|c|c|c|c|c|c|c|}
\hline $\begin{array}{l}\text { Corrida - } \\
\text { Grau do } \\
\text { aço }\end{array}$ & Peça & $\begin{array}{c}\text { Após } \\
\text { lam.intermediáric } \\
\text { (Bar) }\end{array}$ & $\begin{array}{c}\text { Trecho } 1 \\
\text { (Bar) }\end{array}$ & \multicolumn{2}{|c|}{$\begin{array}{c}\text { Trecho } 2 \\
\text { (Bar) }\end{array}$} & $\begin{array}{l}\text { Trecho } 3 \\
\text { (Bar) }\end{array}$ & \multicolumn{2}{|c|}{$\begin{array}{c}\text { Temperatura na } \\
\text { entrada do leito }\left({ }^{\circ} \mathrm{C}\right)\end{array}$} \\
\hline \multirow{10}{*}{$\begin{array}{c}\text { A00063 } \\
1030 D\end{array}$} & 01 & \multirow[t]{4}{*}{0,4} & 13 & \multicolumn{2}{|l|}{4} & 4 & \multicolumn{2}{|r|}{660} \\
\hline & 02 & & 11,5 & \multicolumn{2}{|l|}{6,5} & 6,5 & \multicolumn{2}{|r|}{667} \\
\hline & 03 & & 15 & \multicolumn{2}{|l|}{15} & 15 & \multicolumn{2}{|r|}{-} \\
\hline & 04 & & 15 & \multicolumn{2}{|c|}{15} & 15 & \multicolumn{2}{|r|}{630} \\
\hline & \multicolumn{8}{|c|}{ Pressões e Temperaturas } \\
\hline & Peça & LE (kgf/mm²) & $\operatorname{LR}\left(\mathbf{k g f} / \mathrm{mm}^{2}\right)$ & LR/LE & $\mathrm{Al}(\%)$ & \multicolumn{2}{|c|}{$\begin{array}{l}\text { Massa linear } \\
(\mathrm{kg} / \mathrm{m})\end{array}$} & Dobramento \\
\hline & 01 & 53,0 & 65,7 & 1,314 & 12,1 & \multicolumn{2}{|c|}{6,25} & Ok \\
\hline & 02 & 53,3 & 68,8 & 1,368 & 13,4 & \multicolumn{2}{|c|}{6,25} & Ok \\
\hline & 03 & 53,9 & 67,5 & 1,300 & 14,7 & \multicolumn{2}{|c|}{6,25} & Ok \\
\hline & 04 & 54,2 & 69,5 & 1,282 & 16,3 & \multicolumn{2}{|c|}{6,25} & Ok \\
\hline
\end{tabular}

Figura 9. Parâmetros de processo e resultados obtidos na laminação do aço 1030. 


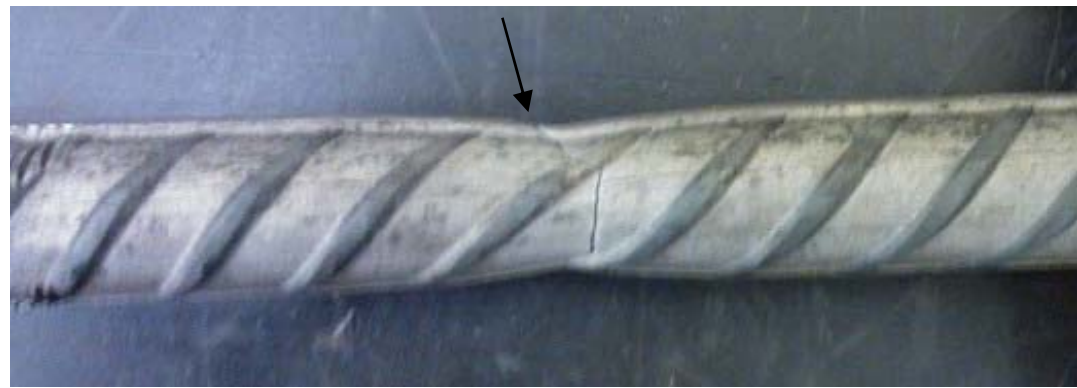

Figura 10. Peça 01 aço 1030D ilustrando a estricção do material.

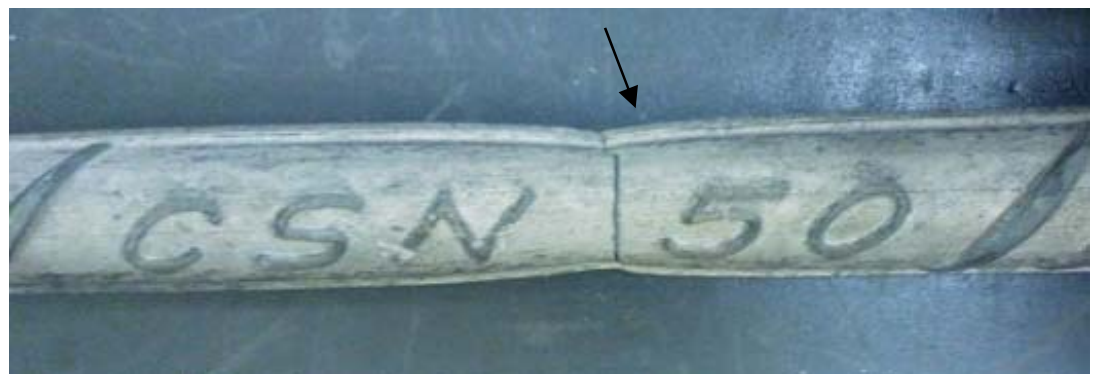

Figura 11. Peça 02 aço 1030D ilustrando a estricção do material.

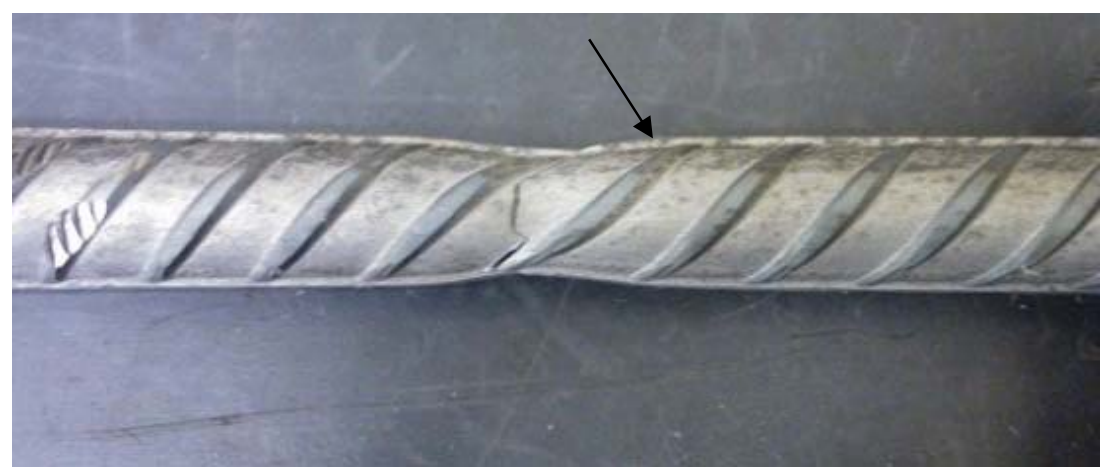

Figura 12. Peça 03 aço 1030D ilustrando a estricção do material.

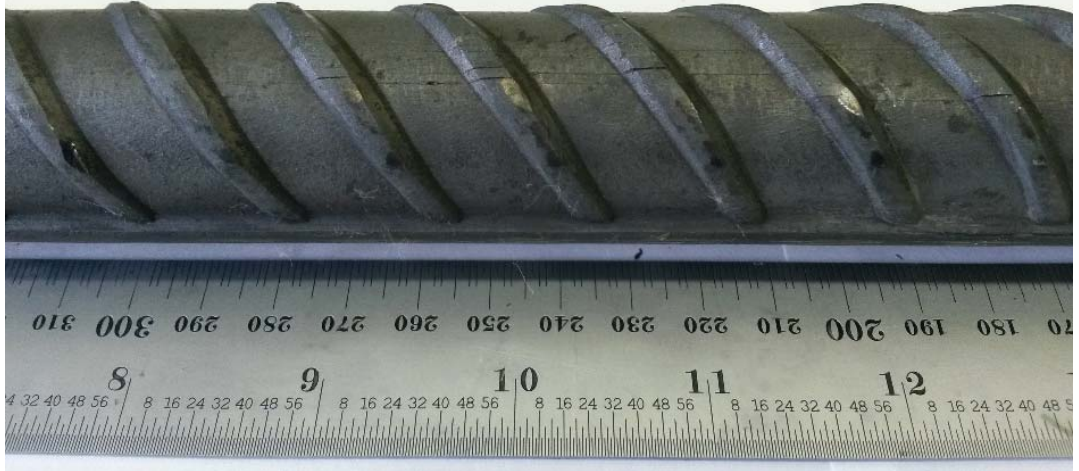

Figura 14. Detalhe do aço 1030D. 

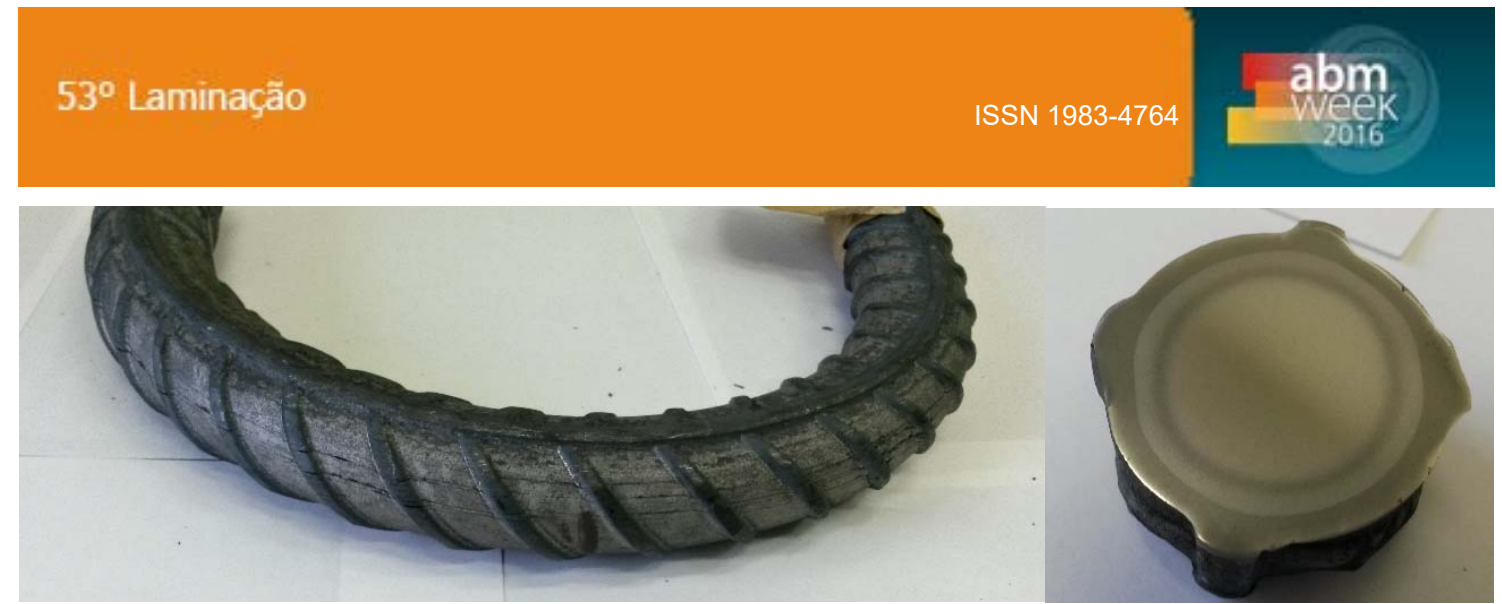

Figura 15. Aspecto da região da nervura após o ensaio de dobramento do aço 1030D e coroa de tratamento térmico.

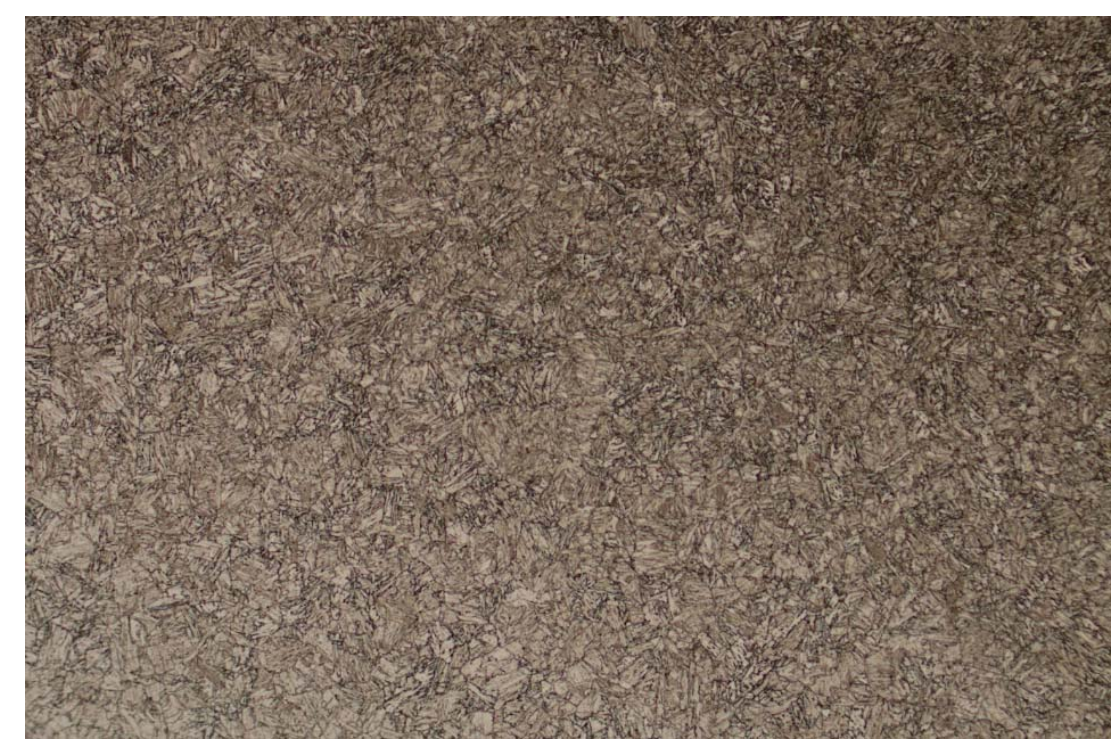

Figura 16. Metalografia do aço na borda 1030D - 100x.

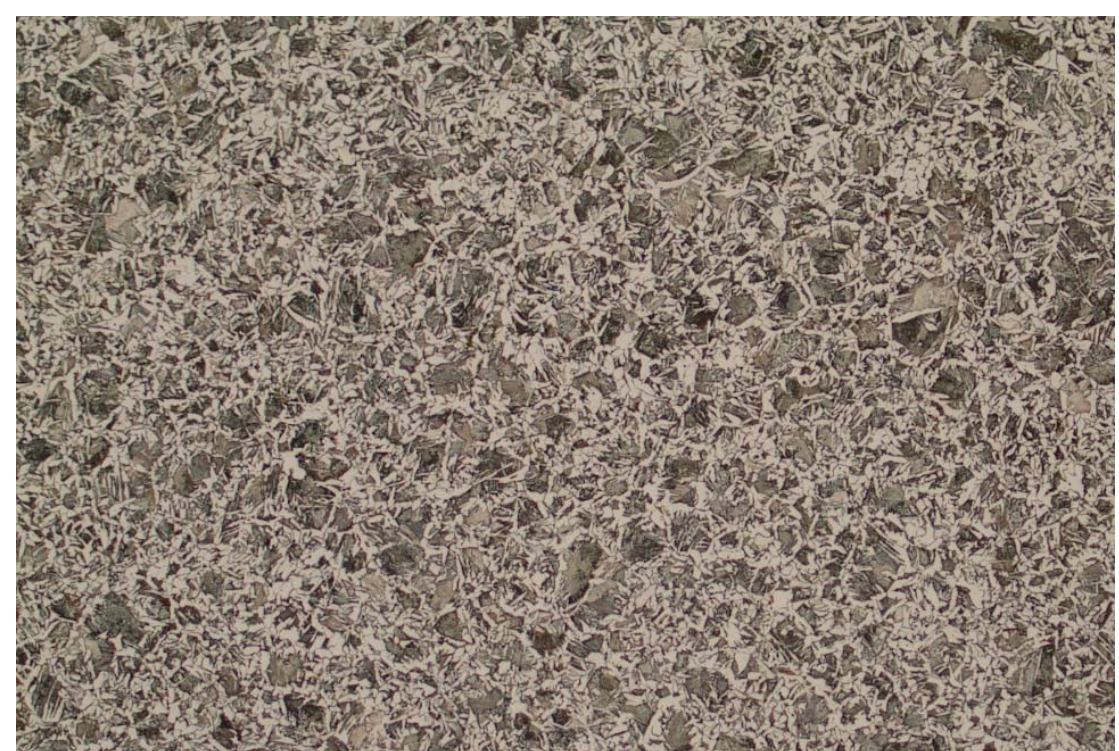

Figura 17. Metalografia do aço na centro 1030D - 100x. 


\subsection{Resultados Aço 1024D}

\begin{tabular}{|c|c|c|c|c|c|c|c|c|}
\hline $\begin{array}{l}\text { Corrida - } \\
\text { Grau do } \\
\text { aço }\end{array}$ & $\begin{array}{l}\mathrm{Peç} \\
\mathrm{a}\end{array}$ & $\begin{array}{c}\text { Após } \\
\text { lam.intermediário } \\
\text { (Bar) }\end{array}$ & $\begin{array}{l}\text { Trecho } 1 \\
\text { (Bar) }\end{array}$ & $\begin{array}{r}\text { Trecho } \\
\text { (Bar) }\end{array}$ & & $\begin{array}{c}\text { Trecho } 3 \\
\text { (Bar) }\end{array}$ & \multicolumn{2}{|c|}{$\begin{array}{c}\text { Temperatura na } \\
\text { entrada do leito }\left({ }^{\circ} \mathrm{C}\right)\end{array}$} \\
\hline \multirow{10}{*}{$\begin{array}{c}\text { A00464 } \\
1024 D\end{array}$} & 01 & \multirow[t]{4}{*}{0,4} & 15 & \multicolumn{2}{|l|}{15} & 15 & \multicolumn{2}{|r|}{ - } \\
\hline & 02 & & 15 & \multicolumn{2}{|l|}{15} & 15 & \multicolumn{2}{|r|}{-} \\
\hline & 03 & & 15 & \multicolumn{2}{|l|}{15} & 15 & \multicolumn{2}{|r|}{-} \\
\hline & 04 & & 15 & \multicolumn{2}{|l|}{15} & 15 & \multicolumn{2}{|r|}{-} \\
\hline & \multicolumn{8}{|c|}{ Pressões e Temperaturas } \\
\hline & $\begin{array}{c}\text { Peç } \\
\text { a }\end{array}$ & LE (kgf/mm²) & LR (kgf/mm²) & LR/LE & $\mathrm{Al}(\%)$ & \multicolumn{2}{|c|}{$\begin{array}{l}\text { Massa linear } \\
(\mathrm{kg} / \mathrm{m})\end{array}$} & Dobramento \\
\hline & 01 & - & - & - & - & \multicolumn{2}{|c|}{-} & - \\
\hline & 02 & - & - & - & - & \multicolumn{2}{|c|}{-} & - \\
\hline & 03 & - & - & - & - & \multicolumn{2}{|c|}{-} & - \\
\hline & 04 & 50,3 & 69,4 & 1,255 & 16,3 & \multicolumn{2}{|c|}{6,25} & Ok \\
\hline
\end{tabular}

Figura 18. Parâmetros de processo e resultados obtidos na laminação do aço 1030.

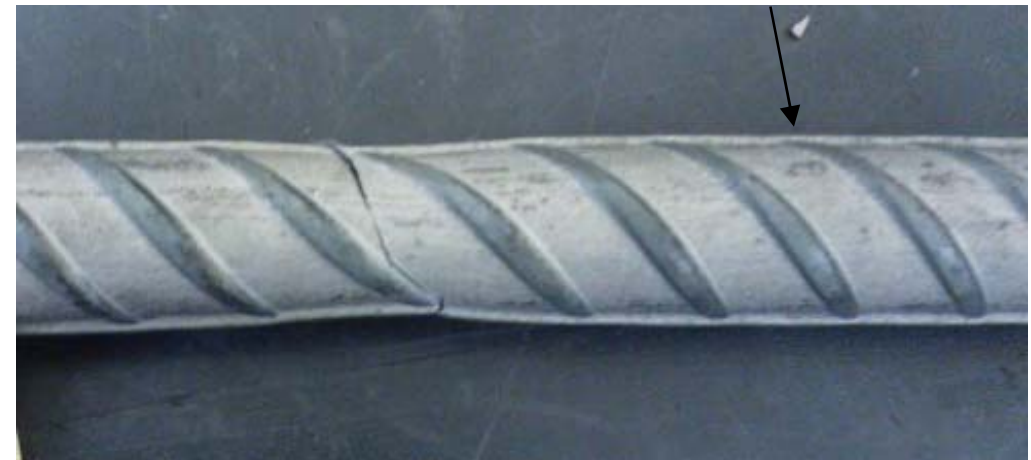

Figura 19. Peça 01 aço 1024D ilustrando a estricção do material.
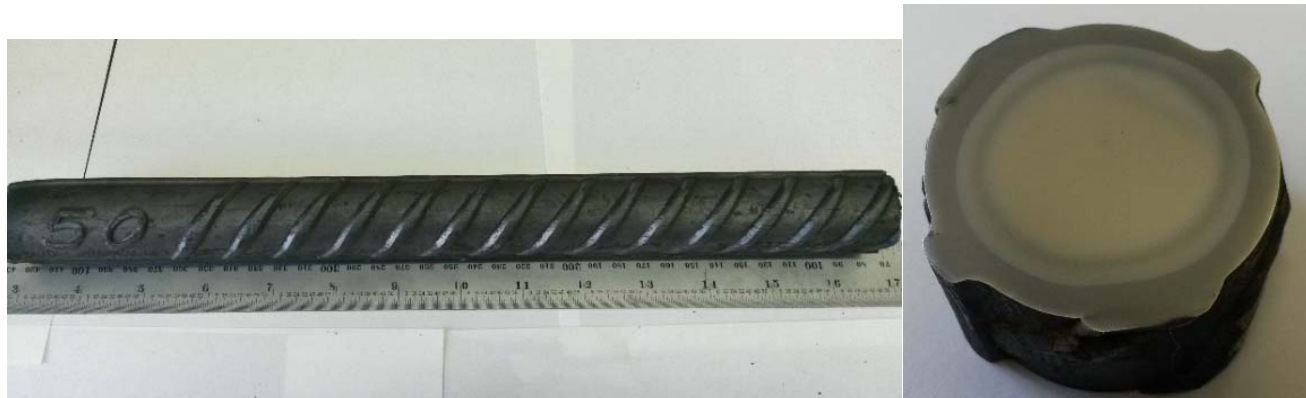

Figura 20. Aspecto da região da nervura após o ensaio de dobramento do aço 1024D e coroa de tratamento térmico. 


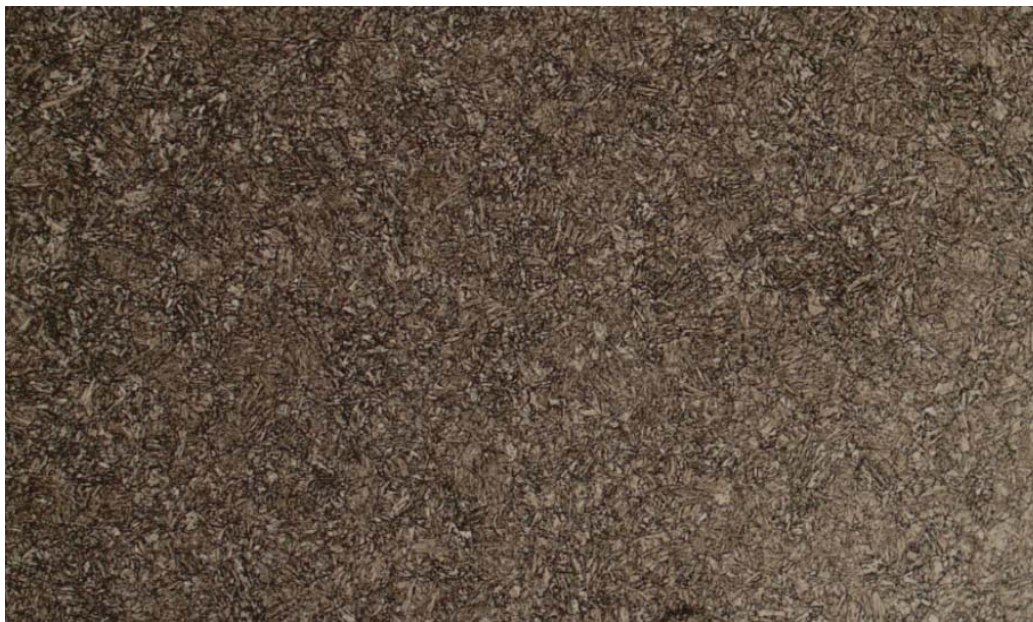

Figura 16. Metalografia do aço na borda 1024D - 100x.

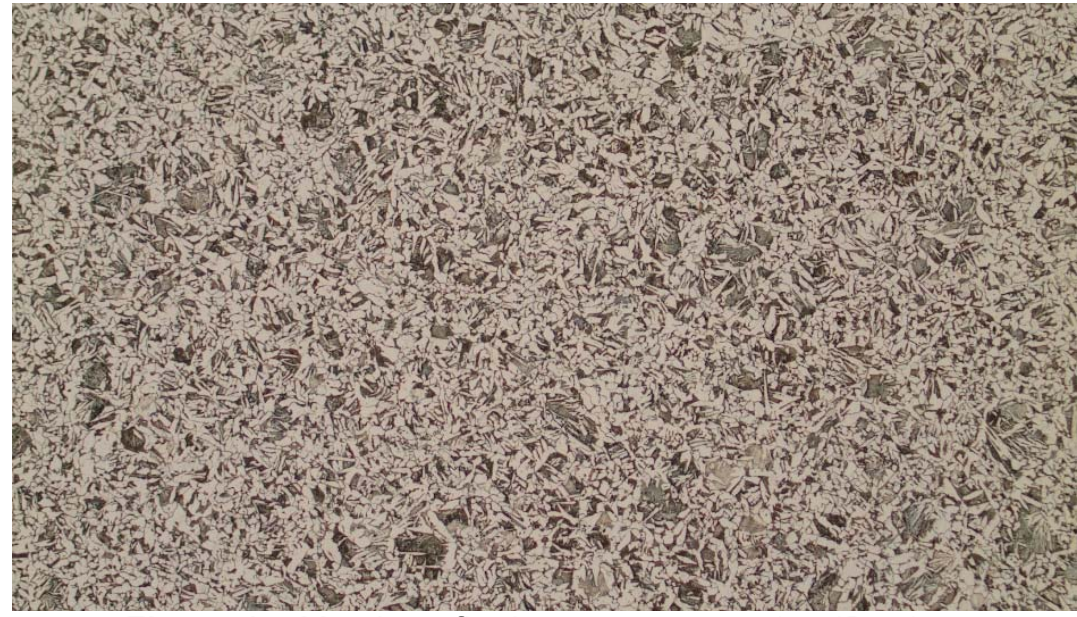

Figura 16. Metalografia do aço na centro 1024D - 100x.

\section{CONCLUSÃO}

Neste trabalho, buscou-se a elaboração, desenvolvimento e documentação para obter maior conhecimento e controle do processo, uma vez que assim, pode-se atingir as microestruturas desejadas e consequentemente as propriedades mecânicas resultantes pelo uso de determinadas taxas de resfriamento. Essas ferramentas também são muito importantes para uma boa parametrização do processo de tratamento térmico.

Para o Aço 1630D não se utilizou o Thermex seguindo diretamente para o leito de resfriamento, não se obteve a propriedade mecânica desejada no limite de escoamento. Para o Aço 1635D não se utilizou o Thermex, seguindo diretamente para o leito de resfriamento, porém obteve-se as propriedades mecânicas desejadas com sucesso.Já para o Aço 1030D utilizou-se o Thermex e obteve-se as propriedades mecânicas desejadas com sucesso, porém o L.E. situou-se em patamares muito próximo do mínimo recomendado pela norma. Para o aço 1024D utilizou-se o Thermex obtendo propriedades mecânicas desejadas com sucesso.

Para escala industrial, após a realização dos testes, o aço que apresentou melhor comportamento é o 1030D. 


\section{Agradecimentos}

Os autores gostariam de agradecer à CSN e aos colaboradores da Laminação pelo apoio e espírito de equipe durante a realização do desenvolvimento do processo.

\section{REFERÊNCIAS}

1 Rizzo, E. M. S. Processos de Laminação de Produtos Longos de Aço. São Paulo, ABM, 2007. 